\title{
Simple innovative comparison of costs between tied-arch bridge and cable-stayed bridge
}

\author{
Järvenpä̈̈ Esko, ${ }^{1, *}$, Quach Thanh Tung ${ }^{2}$ \\ ${ }^{1}$ WSP Finland, Oulu, Finland \\ ${ }^{2}$ WSP Finland, Ho Chi Minh, Vietnam
}

\begin{abstract}
The proposed paper compares tied-arch bridge alternatives and cable-stayed bridge alternatives based on needed load-bearing construction material amounts in the superstructure. The comparisons are prepared between four tied arch bridge solutions and four cable-stayed bridge solutions of the same span lengths. The sum of the span lengths is $300 \mathrm{~m}$. The rise of arch as well as the height of pylon and cable arrangements follow optimal dimensions. The theoretic optimum rise of tied-arch for minimum material amount is higher than traditionally used for aesthetic reason. The optimum rise for minimum material amount parabolic arch is shown in the paper. The mathematical solution uses axial force index method presented in the paper. For the tied-arches the span-rise-ration of 3 is used. The hangers of the tied-arches are vertical-The tied-arches are calculated by numeric iteration method in order to get moment-less arch. The arches are designed as constant stress arch. The area and the weight of the cross section follow the compression force in the arch. In addition the self-weight of the suspender cables are included in the calculation. The influence of traffic loads are calculated by using a separate FEM program. It is concluded that tied-arch is a competitive alternative to cable-stay ed bridge especially when asymmetric bridge spans are considered.
\end{abstract}

\section{Introduction}

Arch bridge is perhaps the best known bridge type. It came to use 2000 years ago [1]. Arches can be classified in many ways like deck arch bridge, tied-arch bridge, through arch bridge, truss arch and most recently network arch. The span range of arch bridge has today reached 552 $\mathrm{m}$ and longer spans are designed. The modern construction material is steel, often used as composite structure with concrete. Many studies have been published lately about arches. Only little has been written about theoretic and practical limits of arch bridges. Already in forties an article was published where the limit of $1000 \mathrm{~m}$ of concrete was found. The allowable stress of the concrete was $15 \mathrm{MPa}$ [2].

Cable-stayed bridge has been a competitive bridge type during recent years. The authors have an opinion that it will be a good time to start to think how competitive arches could be, especially tied-arch bridges.

In this article tied-arch bridge and cable-stayed bridge have been compared to each other using axial force index method. Four tied-arch bridge alternatives and four cablestayed bridge alternatives are studied using the same total length of the bridge and the same span lengths with the same effective width of the deck. Only load bearing material in the longitudinal direction of the superstructure is the basis of comparison.

All bridges have steel and concrete composite deck The bridges have six vehicle lanes. The traffic load follows AASTHO design codes. Multiple presence load factor of 0.65 is used.

\section{Span ranges of tied-arch and cable- stayed bridges}

Tied-arch bridge span range used have been from $50 \mathrm{~m}$ to $550 \mathrm{~m}$. Typical span length for highway bridges is from $75 \mathrm{~m}$ to $250 \mathrm{~m}$. The competitive span range of cablestayed bridge has been from $100 \mathrm{~m}$ to $1200 \mathrm{~m}$. Typical spans lengths have been from $150 \mathrm{~m}$ to $500 \mathrm{~m}$. The development of cable-stayed bridges during last three decades has been powerful, especially in construction and cable technology [3]. The development of arch bridges has been waiting. In China truss-type arch ribs and steel box arches have broken records [4], [5]. Many resent articles handle about network arches and especially their optimal suspender arrangements. Anyhow, the rise of arch is the first priority of the optimal solution, because the arch itself represents half of structural steel amount of the longitudinal load-bearing structures.

\section{Cost comparison method}

\subsection{Design basis of the alternatives}

This study was prepared in order to get general understanding about the reasons and differences of costs between tied-arch bridge and cable-stayed bridge. The basis for the study is that all the bridge alternatives are balanced structures for permanent load. The shape of arch

\footnotetext{
* Corresponding author: eojarvenpaa@gmail.com
} 
is moment-less arch which has only small local bending moments depending of the suspender distances.

Each alternative has been proposed keeping in mind good technical solutions. In the arch alternatives the rise of the arch is the key question. The theoretic optimum rise for material minimum is shown in the Chapter 3. The height of the pylon in the cable-stayed follows the optimum height being about $30 \%$ of the span to the topmost cable anchorage in the tower.

\subsection{Calculations}

\subsubsection{General}

The dead load of the superstructures has been preliminary calculated as composite structure assuming the width of the deck for six vehicle lanes. The weight of the half deck is $150 \mathrm{kN} / \mathrm{m}$. Because of the traffic load has bigger partial safety factor than the dead load it has been multiplied by the factor of $1.75 / 1.35$.

\subsubsection{Permanent loads and moment-less arches}

The shape of arch for the permanent load forces has been calculated by iterative method which results moment-less shape of the arch. In the calculation, the arch is divided into 62 straight members. The analys is takes into account the self-weight of the hangers based on stresses used. In high arches the weight of hangers has influence to the final forces in the structures and also to moment-less geometry of the arch. The weight of the arch follows the increase of axial forces of the arch in the iteration from top to the bearing level. The arch, at the crown has the weight of $13.3 \%$ from the weight of deck. Only the calculations results are shown in this paper-

\subsubsection{Permanent loads for cable stayed bridge}

The forces in the cable-stayed bridges are calculated from the deck weight including the weight of cables. The cable forces of the permanent loading give zero displacement to the girder in vertical direction and to the tower in horizontal direction. The sizes of the cables vary according the loads.

\subsubsection{Traffic load calculations}

The preliminary cross sections of the members are given for traffic load calculations. The traffic load consists of the load of trucks and lane loads. Impact factor of 1.33 and multiple presence factor of 0.65 are applied. The used values of truck for half the deck width are $91 \mathrm{kN}+376 \mathrm{kN}$ $+376 \mathrm{kN}$. The distances of the axels are $4.3 \mathrm{~m}$ and $4.3 \mathrm{~m}$ to $9.0 \mathrm{~m}$. The lane load for half of the deck is $18 \mathrm{kN} / \mathrm{m}$ when multiple presence factor is used. The calculation program is RM Bridge, which results maximum stresses based on the influence lines of the stresses.

\subsection{Axial force index method}

A concept of axial force index $i_{a}$, has been utilized in cost comparisons. The index is changed to volumes and material amounts and finally to material costs. Axial force index is defined by equation

$$
i_{a x}=\sum_{i=1}^{n} F_{i} L_{i}
$$

where $F_{i}$ is the member axial force, $L_{i}$ is the member length, and $n$ is the number of members respectively.

In the he cable-stayed bridge the axial force index $\left(i_{a x}\right)$ is the sum of axial force indexes of the cables $\left(i_{c}\right)$, tower $\left(i_{t}\right)$ and girder $\left(i_{g}\right)$. The tied-arch bridges have axial force indexes of the $\operatorname{arch}\left(i_{a}\right)$, the tie-girder $\left(i_{t}\right)$ and suspension hangers $\left(i_{h}\right)$. The relative cost $\mathrm{c}$ of each structural member can be calculated from the index by dividing it by stress used and multiplied by the density of the material and by the unit price.

$$
c=i_{a} \varrho \mathrm{\gamma} / \delta
$$

where $i_{a}$ is the axial load index of the member in the structure, $Q$ is the density of the material, $\gamma$ is the unit price of the member and $\delta$ is the stress used.

\subsection{Relative cost comparison}

One needs to make decisions of the axial stress of the cables, suspenders and steel structures in order to get the volume of the materials.

The stress level in the cables and suspenders is estimated to be on the level of $700 \mathrm{MPa}$. Only dead weight and traffic loads and taken into consideration. This value is used also in the tie-girder for permanent loads. The tie girder takes tension and bending moments after the final connection to the arch. The tension of permanent load is taken by pre stressed cables.

In the comparisons, the arch and the tower are steel structures. In practise, the tower might be a concrete structure. This can improve the competitiveness of the cable-stayed bridges, but the marginal is not anyhow determinative in these comparisons.

The value of $160 \mathrm{MPa}$ is used as stress level in the steel for arch, tower, girder and tie-girder. The calculations do not consider neither any other loadings nor stability or nonlinear effects.

Unit price used for cables is 18.0 Euro $/ \mathrm{kg}$ and for steel structures 6.0 Euro $/ \mathrm{kg}$.

Table 1. Calculation values used for steel structures

\begin{tabular}{|l|c|c|}
\hline Member & Stress $\delta$ & Unit price $\gamma$ \\
\hline Cables & $700 \mathrm{MPa}$ & $18 € / \mathrm{kg}$ \\
\hline Arch & $160 \mathrm{MPa}$ & $6 € / \mathrm{kg}$ \\
\hline Girder and tower & $160 \mathrm{MPa}$ & $6 € / \mathrm{kg}$ \\
\hline Suspenders & $700 \mathrm{MPa}$ & $18 € / \mathrm{kg}$ \\
\hline \multicolumn{2}{|c|}{ Density of steel $\varrho=8000 \mathrm{~kg} / \mathrm{m}^{3}$} \\
\hline
\end{tabular}




\subsection{Axial force index from bending moments}

For permanent loads there are only minor bending moments in the continuous deck girder, spans of 12.0..12.5 meters between the anchoring points of the cables and hangers. This bending moment does not influence to the comparisons being on the same level in each alternative. The bending moment is the force pair with the moment arm of $d$ in the cross section from compression force centroid to tension force centroid. The axial force indexes from the bending moment of traffic loads is calculated from the compression and tension forces of the girder flanges.

The bending moment calculations from traffic loads needs stiffness relations of the structure members. For practical engineer, the easiest way is to give the preliminary dimensions of the members to the calculation program. The axial forces in these comparisons are calculated by multiplying the flange area and the flange stress of I-girder with thin web. The axial force index of the whole girder is the force integral over the member length along both of the flanges.

The axial force total index of the constant cross section girder $i_{g m}$ from the bending moment $M_{x}$ and the axial force $N_{x}$ is

$$
i_{g m=}=\left|2 \int_{0}^{l} \frac{M_{x}}{d} \mathrm{dx}\right|+\left|\int_{0}^{l} N_{x} \mathrm{dx}\right|
$$

where $\mathrm{d}$ is the distance between the tension and compression side centroid of the cross section.

The compression and tension from bending moment $M_{x}$ need to be calculated separately because of the axial force $N_{x}$. When combining index values one has to notice to calculate the sum only from those indexes which add the indexes of compression or tension.

In the arch rib the governing stress from permanent load is compression. Only the maximum compression stresses at top flange and at bottom flange from the traffic loads are taken into account. The tension stresses do not influence to the steel amount of the arch. The same is valid in the tie-girder for tension.

The bending moments cause also shear forces. It also can be changed to index value. The shear is not handled because of its small values compared to axial indexes. In the more exact calculations for live loads it has to be taken into account. The shear index is

$$
i_{s h}=\left|\int_{0}^{l} Q_{x} \mathrm{dx}\right|
$$

In the cable-stayed bridge the axial compression force of the girder from traffic load does not normally add material usage in composite structure because the compression minimizes tension stresses and it is utilized in concrete deck slab design. In the cable-stayed bridge alternatives only the tension in the bottom flange is included in the index calculation.

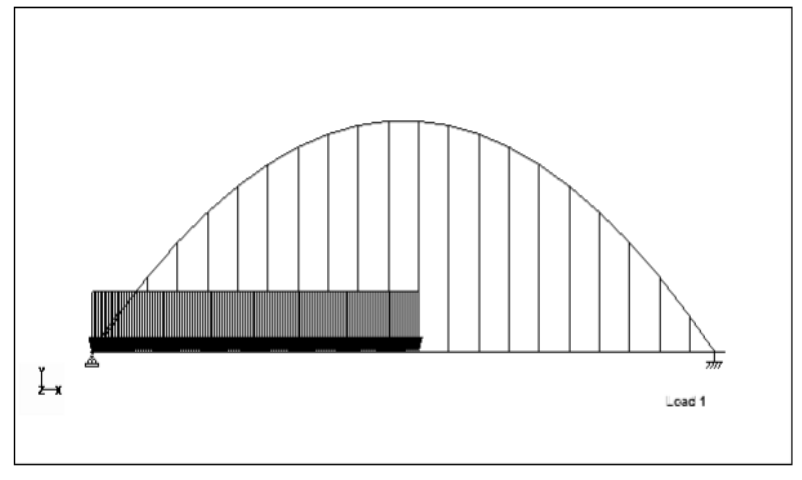

Figure 1. Typical asymmetric loading location.

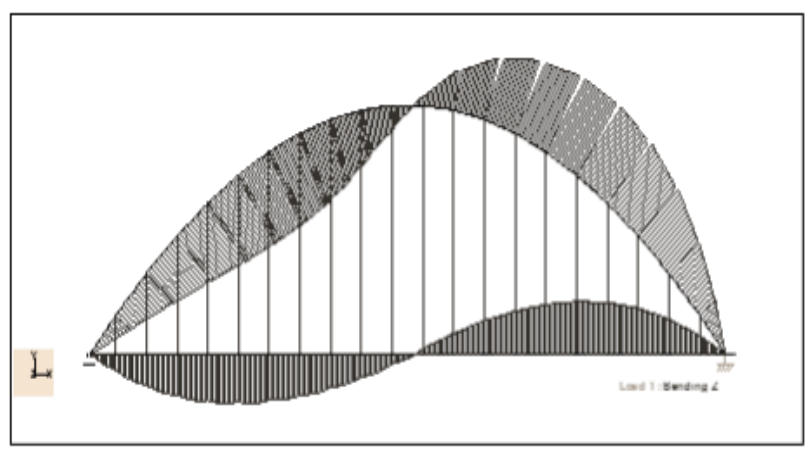

Figure 2. Bending moments from asy mmetric loading.

In the tied-arch bridges traffic load gives bending moments, which are both positive and negative (Figure 1 and Figure 2. In the tie-girder flanges, both of the girder flanges get tension and are accordingly included to the index of the tie-girder, because the governing stress from permanent load is tension ( Figure 3 and Figure 4).

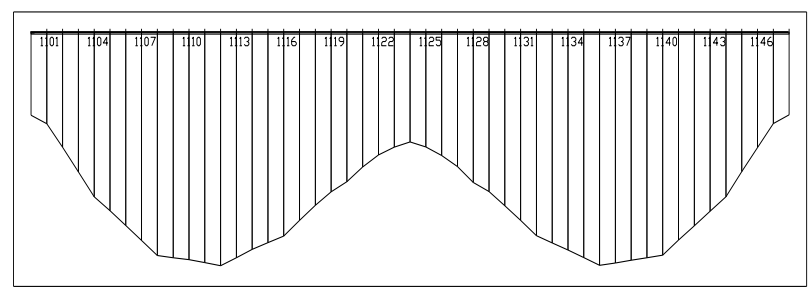

Figure 3. Maximum tension envelope in tie-girder top flange.

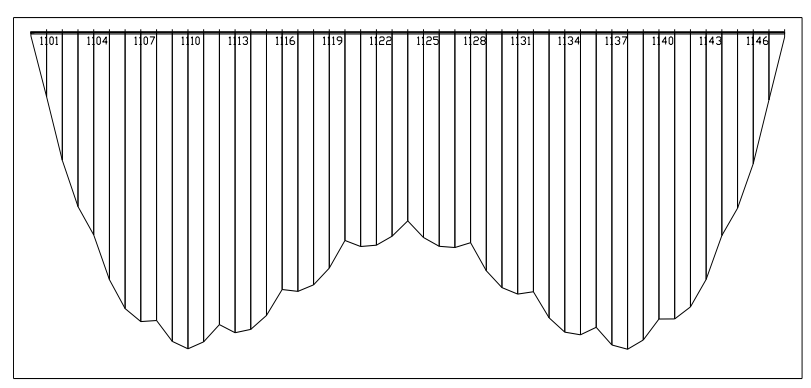

Figure 4. Maximun tension envelope in tie-girder bottom flange. 


\section{Rise selection for tied-arch}

\subsection{Generally accepted optimum rise and shape of arch}

Tied-arches are mostly designed using the rise ratio of $l / 4$ to $l / 5$ [6]. In the flat landscape even more lower arches give pleasing outlook. Over deep valleys, in mountainous landscape and over the rivers between highrise buildings a high arch could also be a beautiful structure. The most famous landmark arch is St Luis Gateway arch, with a span and rise of $192 \mathrm{~m}$ [7]. The used relation of $l / h$ is 1 . The arch is a moment-less, close to uniform stress arch, where the cross section grows as the compression of the arch increases towards the arch pin.

The optimum rise of arch is not well-known figure. Generally used rises are expected to follow the optimum height. When choosing the rise of the arch one should notice that the arch itself represents about $50 \%$ of the steel amount of longitudinal bearing structures. Tie-girder and the suspenders are the rest half.

Parabolic arch is a good, first estimate for the arch dimensioning. Anyhow, the correct solution for the shape of arch bridge is the moment-less shape for permanent loads. It is always important to avoid eccentricity of the high compression forces in the arch rib resulting the bending stresses from the eccentricity [8]. The difference from moment-less shape to parabola shape is not noted by eye, but is noted in the needed structural thickness of the arch and in the costs of construction and maintenance of the bridge.

\subsection{Theoretic optimum rise of parabola}

The minimum of the axial force index of the arch represents also the minimum material amount of the arch. We approach this with the parabola of uniform vertical load on the arch.

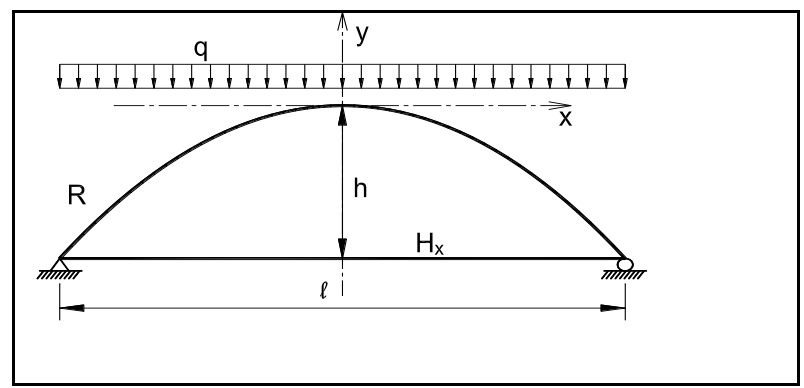

Figure 5. Parabolic arch.

The equation of the parabolic arch is

$$
\mathrm{y}=-\frac{4 h}{l^{2}} x^{2}, \text { then } \frac{d y}{d x}=-\frac{8 h}{l^{2}} \mathrm{x}
$$

The horizontal tension force, which is needed to result pin ended structure, in the tie is

$$
H_{x}=\frac{q l^{2}}{8 h}
$$

The compression force $R_{S}$ in the arch rib is

$$
R_{s}=H_{x} \sqrt{1+\left(\frac{d y}{d x}\right)^{2}}
$$

The differential length of the arch is

$$
d s=\sqrt{1+\left(\frac{d y}{d x}\right)^{2}}
$$

The axial force index $i_{a}$ for the arch is

$$
\begin{gathered}
i_{a=} 2 \int_{0}^{l / 2} R_{x} d s, \\
i_{a}=2 \int_{0}^{l / 2} H_{x} \sqrt{1+\left(\frac{d y}{d x}\right)^{2}} \sqrt{1+\left(\frac{d y}{d x}\right)^{2}} d x
\end{gathered}
$$

This leads to equation

$$
i_{a}=2 \int_{0}^{l / 2} \frac{2 q l^{2}}{8 h}\left(1+\frac{64 h^{2}}{l^{4}} x^{2}\right) d x
$$

The definite integral is

$$
i_{a}=2 q\left(\frac{l^{3}}{16 h}+\frac{h l}{3}\right)
$$

For finding the minimum index value we derivative $i_{a}$ in relation to arch rise and set the derivative equal to zero. This results the height of arch giving the minimum material amount to the parabolic arch for uniform load of

$$
\mathrm{h}=\frac{l \sqrt{3}}{4}
$$

The optimum span-rise relation $l / h$ of the arch is 2,309 . The same value is given in the reference [6]. Numerical calculations results the same value. The Figure 6 shows the influence of $l / h$ relation to material usage of uniform load parabolic arch.

It is important to notice that in a tied-arch bridge, without the self-weight of the arch, the axial force index value of the arch is $50 \%$ of total axial force index of the structure. The sum of indexes of tie-girder $\left(i_{t}\right)$, and hangers $\left(i_{h}\right)$ is the other $50 \%$ of the total index.

The axial force index of the tie is

$$
i_{t}=\frac{q l^{3}}{8 h}
$$

and when assuming that the load $\mathrm{q}$ is carried by hangers, as in tied-arch bridges, the index for hangers, calculated as curtain structure, is

$$
i_{h}=\frac{2 q l h}{3}
$$

The sum of compression force indexes of the structure is equal to the sum of tension for indexes. This is valid for 
outer loads. The hangers and the tie-girder do not change the optimum height result of parabolic arch when the arch is loaded by outer vertical uniform load.

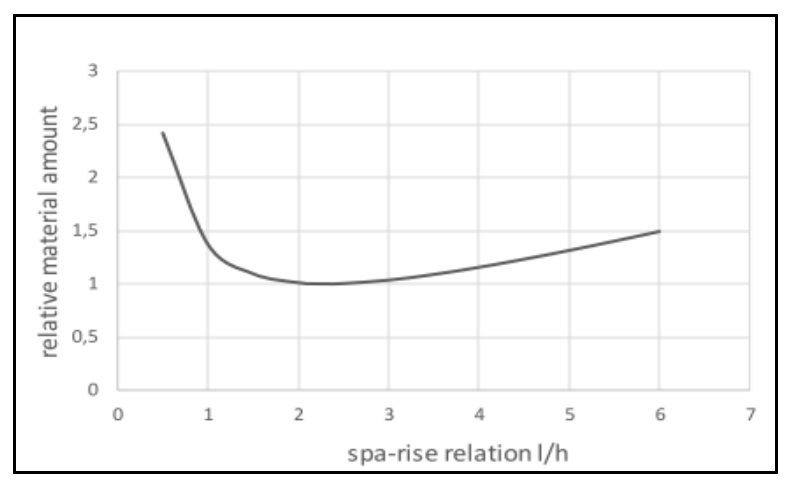

Figure 6. Relative load-carrying material amount of parabolic arch in relation to $l / h$.

\section{Alternative preliminary designs}

The basis for design is given in the Chapter 3. The crosssections of the structural members follow the dimensions used in designed and built bridges. The tension for the permanent load has taken by high strength steel cables before fixing the deck girders to arch. The deck girder and the arch are corrected by hinge structures to each other. The following pictures show the bridge alternatives:

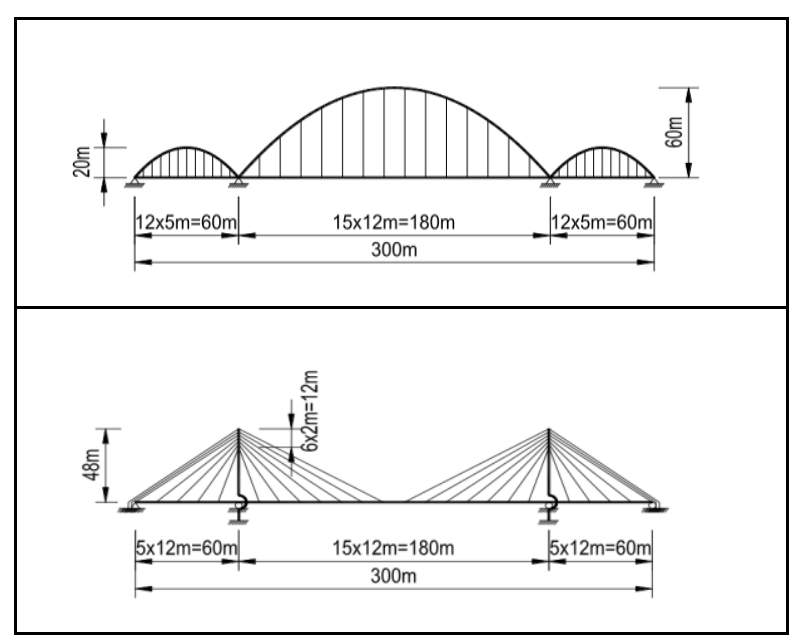

Figure 7. Three-span alternatives compared.

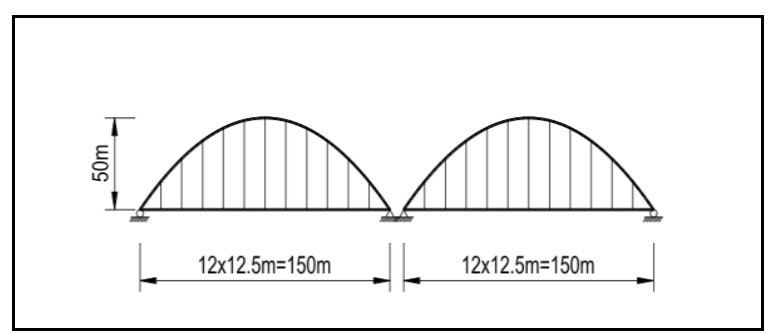

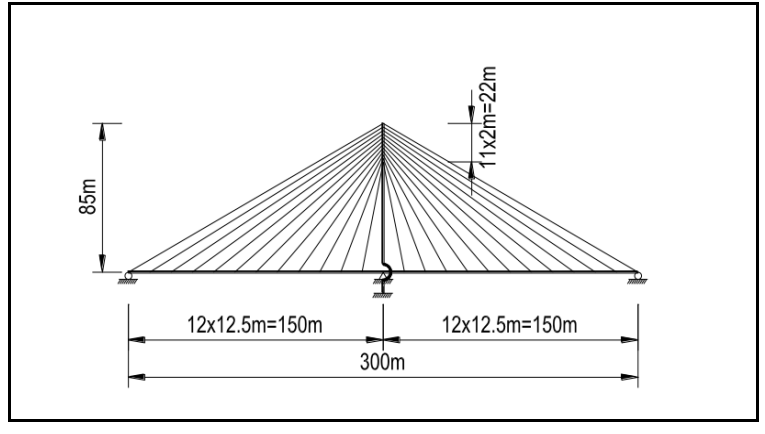

Figure 8. Two-span symmetric alternatives compared

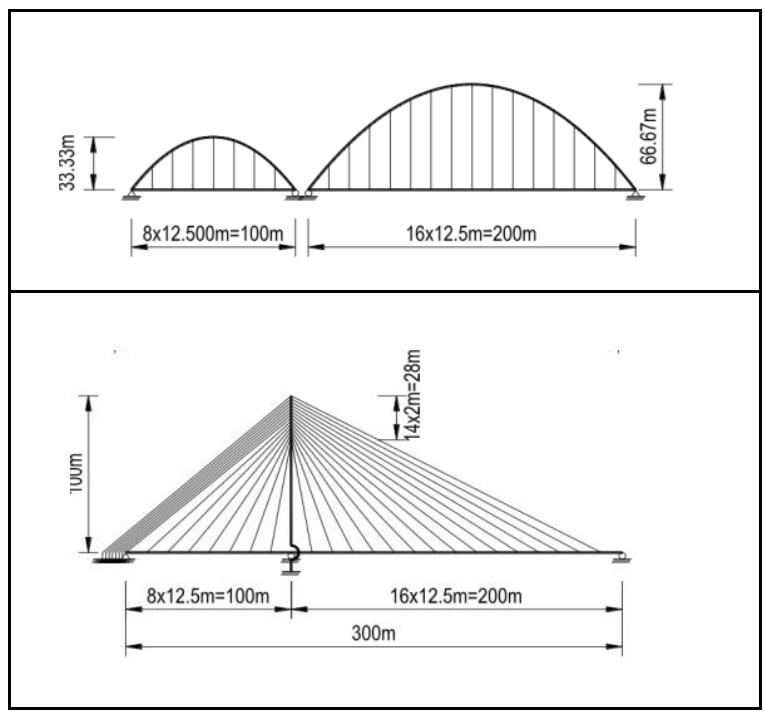

Figure 9. Two-sp an asymmetric alternatives.

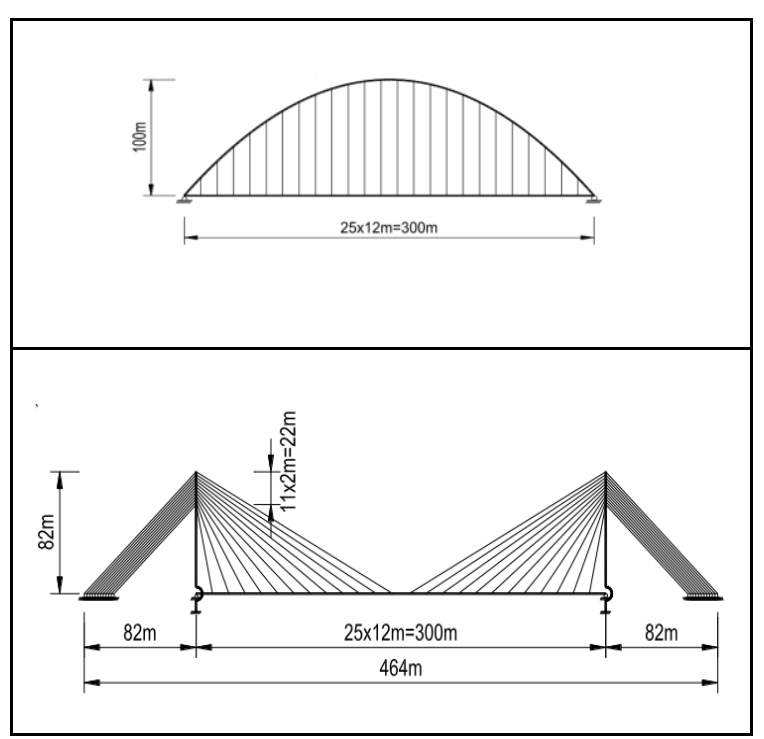

Figure 10. Single-span alternatives compared 


\section{Cost comparison results}

\subsection{General findings}

In the tied-arch bridges the index of arches, and in the cable-stayed bridge the index of cables, represents about $50 \%$ of the total index. It indicates that good first estimate will be got by evaluating only the arch and the cables.

In the following cost comparison tables the total cost represents only $25 \ldots 40 \%$ of the total cost of these bridges.

\subsection{Comparative indexes and costs}

The following tables give the results of index calculations for half of the deck. At the end of each table the total cost of the load-carrying material is given for the whole deck.

Table 2. Indexes and cost comparison of tree-span bridges.

\begin{tabular}{|c|c|c|c|c|c|}
\hline Arch & Girder & Hanger & Cable & Girder & Tower \\
\hline \multicolumn{6}{|c|}{ Permanent load axial index } \\
\hline 3924 & 2436 & 1294 & 5277 & 2490 & 2546 \\
\hline \multicolumn{2}{|l|}{ Sum } & 7654 & Sum & & 10313 \\
\hline \multicolumn{6}{|c|}{ Traffic load axial index } \\
\hline 2529 & 2552 & 346 & 1440 & 1950 & 556 \\
\hline \multicolumn{2}{|c|}{ Sum } & 5426 & Sum & & 3947 \\
\hline \multicolumn{6}{|c|}{ Sum of indexes, half of the deck } \\
\hline \multirow{2}{*}{\multicolumn{2}{|c|}{\begin{tabular}{c|c}
6453 & 4988 \\
Sum & {$[\mathrm{MNm}]$}
\end{tabular}}} & 1640 & 6717 & 4440 & 3102 \\
\hline & & 13080 & Sum & $\mathrm{MNm}]$ & 14260 \\
\hline \multicolumn{6}{|c|}{ Comparative material costs, the whole deck } \\
\hline Total & & 6946799 & $€$ & & 152498 \\
\hline
\end{tabular}

The symmetric cable-stayed bridge alternative and three tied-arches show equal costs. It is worth noting the traffic load influence is $37.4 \%$ higher in the tied-arch bridge. The amount of steel in the arches is $645300 \mathrm{~kg}$ and costs $3871800 €$. The amount of the stay-cables is $153531 \mathrm{~kg}$ and costs $2763558 €$.

Table 3. Indexes and cost comparison of two-span bridges.

\begin{tabular}{|c|c|c|c|c|c|}
\hline Arch & Girder & Hanger & Cable & Girder & Tower \\
\hline \multicolumn{6}{|c|}{ Permanent load axial index } \\
\hline 4770 & 2959 & 1671 & 7523 & 4368 & 3250 \\
\hline \multicolumn{2}{|c|}{ Sum } & 9400 & \multicolumn{2}{|l|}{ Sum } & 15141 \\
\hline \multicolumn{6}{|c|}{ Traffic load axial index } \\
\hline 3181 & 3140 & 371 & 1864 & 2977 & 1092 \\
\hline \multicolumn{2}{|l|}{ Sum } & 6692 & \multicolumn{2}{|l|}{ Sum } & 5933 \\
\hline \multicolumn{6}{|c|}{ Sum of indexes, half of the deck } \\
\hline 7951 & 6099 & 2042 & 9387 & \begin{tabular}{|l|}
7345 \\
\end{tabular} & 4342 \\
\hline Sum & [MNm] & 16092 & Sum & {$[\mathrm{MNm}]$} & 21070 \\
\hline \multicolumn{6}{|c|}{ Comparative material costs, the whole deck } \\
\hline Total & & 8335593 & $€$ & \multicolumn{2}{|c|}{10884773} \\
\hline
\end{tabular}

The cable-stayed bridge has $30.5 \%$ higher costs than the tied-arch. The tied-arch bridge for permanent load has remarkable advantage. The traffic load influence in the tied-arch is $12.8 \%$ higher than in the cable-stayed bridge. The load-carrying amount of the steel in the arch ribs is $795110 \mathrm{~kg}$ and the costs $4570660 €$. The amount of the stay-cables is $214560 \mathrm{~kg}$ and costs $3862080 €$.

Table 4. Indexes and cost comparison of asymmetric twospan bridges.

\begin{tabular}{|c|c|c|c|c|c|}
\hline Arch & Girder & Hanger & Cable & Girder & Tower \\
\hline \multicolumn{6}{|c|}{ Permanent load axial index } \\
\hline 4964 & 3081 & 1633 & 12526 & 6145 & 6645 \\
\hline \multicolumn{2}{|c|}{ Sum } & 9678 & \multicolumn{2}{|l|}{ Sum } & 25316 \\
\hline \multicolumn{6}{|c|}{ Traffic load axial index } \\
\hline 3181 & 3141 & 370 & 2205 & 2808 & 1092 \\
\hline \multicolumn{2}{|c|}{ Sum } & 6692 & \multicolumn{2}{|l|}{ Sum } & 6105 \\
\hline \multicolumn{6}{|c|}{ Sum of indexes, half of the deck } \\
\hline 8145 & 6222 & 2004 & 14731 & 8953 & 7737 \\
\hline Sum & {$[\mathrm{MNm}]$} & 16370 & Sum & {$[\mathrm{MNm}]$} & 31421 \\
\hline \multicolumn{6}{|c|}{ Comparative material costs, the whole deck } \\
\hline Total & & 8697259 & $€$ & \multicolumn{2}{|c|}{15773272} \\
\hline
\end{tabular}

Asymmetric cable-stayed has $81.3 \%$ higher costs. The difference is remarkable. Difference in traffic load is about $9.6 \%$ in favour of cable-stayed bridge. The amount of steel in the arches is $814500 \mathrm{~kg}$ and costs $4885700 €$ The amount of the stay-cables is $336708 \mathrm{~kg}$ and costs $6060754 €$.

The costs above do not include remarkable costs of needed ballast load against uplift of $37 \mathrm{MN}$ from the cables at back span abutment.

Table 5. Indexes and cost comparison of single-pan bridges.

\begin{tabular}{|c|c|c|c|c|c|}
\hline Arch & Girder & Hanger & Cable & Girder & Tower \\
\hline \multicolumn{6}{|c|}{ Permanent load axial index } \\
\hline 8977 & 5572 & 2940 & 14788 & 7775 & 7007 \\
\hline \multicolumn{2}{|l|}{ Sum } & 17489 & \multicolumn{2}{|l|}{ Sum } & 29570 \\
\hline \multicolumn{6}{|c|}{ Traffic load axial index } \\
\hline 3962 & 3912 & 696 & 3229 & 2926 & 1252 \\
\hline \multicolumn{2}{|l|}{ Sum } & 8571 & \multicolumn{2}{|l|}{ Sum } & 7407 \\
\hline \multicolumn{6}{|c|}{ Sum of indexes, half of the deck } \\
\hline 12939 & 9484 & 3637 & 18017 & 10701 & 8259 \\
\hline Sum & $\mathrm{MNm}]$ & 26060 & Sum & {$[\mathrm{MNm}]$} & 36977 \\
\hline \multicolumn{6}{|c|}{ Comparative material costs, the whole deck } \\
\hline Total & & 3638809 & $€$ & \multicolumn{2}{|c|}{18436619} \\
\hline
\end{tabular}

The cable-stayed bridge has $35.1 \%$ higher costs than the tied-arch alternative. The tied-arch bridge for permanent load has remarkable advantage. The traffic load influence in the tied-arch is $15.7 \%$ higher than in the stay-cable bridge. The amount of steel in the arch is 
$1293900 \mathrm{~kg}$ and costs $7763400 €$. The amount of the stay-cables is $411817 \mathrm{~kg}$ and costs $7412709 €$.

The costs above do not include remarkable costs of needed ballast load against uplift of $45 \mathrm{MN}$ from the cables at back at both of the abutments .

\section{Discussion}

\subsection{Rise of arch}

The arch span length and rise relation $l / h=3$ is used in the study. This is beyond the normally used rise relation of 5 to 6 . If the value of 5 were used, it would add permanent axial load index sum by $20 . .25 \%$. As an example in the symmetric two-span bridge, it would add costs of superstructure by $14 \%$.

\subsection{Bending moments from traffic load}

As noted earlier, the disadvantage of the arch with vertical hangers is the bending moments in the arch and the tiegirder from live loads. The rise of arch is important for long span bridges because of high permanent loads but it does do not control the bending moment from traffic loads; the moments are related to $0.36 \mathrm{x}$ span length [7]. Network arch mitigates the bending moments [10].

\subsection{Long span arches}

A comparative study was prepared with span lengths of $240+600+240 \mathrm{~m}$ the deck as orthotropic steel structure.. The cost difference between the tied-arch and the cable stayed bridge is small. Deeper analysis by variating used stresses and unit prices were useful.

\subsection{Other important design question}

This study compares tied-arch bridge to cable-stayed bridge only by using linear static calculations. The supposition in the comparison done is that all the other important design problems, such as wind, fatigue, stability and cable vibrations does not influence to the results.

\section{Conclusions}

The calculations show that tied-arch is a competitive bridge structure compared to stay-cable bridge. The rise of the arch should be studied case by case, not only stick to the traditional span-rise relations. Big-span arches have not seen yet their daylight with crossing hangers and taken the tension of tie-girder from permanent loads by pre stressing cables. Moment-less arch for permanent loads and the well-studied rise of the arch should be used.

\section{References}

1. Martinez, S. P-F. (2007). Arches: Evolution and future trends,Ferrovial-Argoma, Madrid, Spain https://caminstech.upc.edu/sites/default/files/Arch es\%20Evolution\%20 and\%20Future\%20Trend.pdf

2. Baravelle, F. (1936). The theoretical maximum spans of reinforced concrete arch bridges, IABSE congress report, http://www.e-periodica.ch

3. Svensson, H. (2012). Cable-stayed Bridges 40 Years of Experience World Wide, Erns t\& Sohn GmbH \& Co, ISBN978-433-02992-3

4. Chen,S.,Nakamura, S.,Chen,B.,Wu,Q.,Nishikawa,T ,(2013). Comparison between steel arch bridges in China and Japan, Journal of JSCE, Vol. 1, 214-227

5. Chen, B. (2007). An overview of concrete and CFST arch bridges in China. www.hms.civil.uminho.pt $>\operatorname{arch} 2007$

6. Nettleton, D. (1977). Arch Bridges, The University of Texas at Austin, txu-oclc-25398289.pdf, http://hdf.handle.net/21 52/14231

7. Osserman, R. (2010). How the Gateway Arch Got its Shape. Nexus Network Journal 12 (2), doi: 10.1007/s00004-010-0030-8, published on-line 5 May 2010

8. Lewis,W.,(2016).Mathematical model of a moment-less arch. Proceedings of the Royal Society A, doi: 10.1098/rspa.2016.0019

9. Tyas,A.,Pichugin,A.V.,Gibert,M.,(2010) Optimum structure to carry a uniform load between pinned supports: exact analytical solution, Proceedings of the Royal Society, published 20 October. DOI: 10.1098/rspa.2010.0376

10. Tveit, P. (2009). Genesis and development of the network arch, NSBA World Steel Bridge Symposium in San Antonio, USA. November 2009. https://home.uia.no/.../Genes is $\% 20$ and $\% 20 \mathrm{D}$ ev elo pment $\% 20$ of $\% 20 t$ 